\title{
Home exercises for pelvic floor in continent women one year after physical therapy treatment for urinary incontinence: an observational study
}

\author{
Exercício domicilar para o assoalho pélvico em mulheres continentes após \\ tratamento fisioterapêutico para incontinência urinária: um estudo observacional
}

\author{
Ana P. Krüger', Soraia C. T. Luz², Janeisa F. Virtuoso'
}

\begin{abstract}
Objectives: To describe the results of home exercise targeting the pelvic floor in continent women one year after the end of a physical therapy treatment for the following outcomes: functional assessment of the pelvic floor and urinary incontinence. Methods: This is an observational study that evaluated fifteen women one year after physical therapy treatment for Stress Urinary Incontinence (SUI). The outcomes for this study were: situations of urinary loss, use of daily protection, practice of home exercises for the pelvic floor, functional assessment of the pelvic floor (FAPF) and patient satisfaction. We also investigated some confounding variables such as hormonal status, number of vaginal deliveries and previous history of episiotomy. Results: One year after completion of physical therapy treatment, we observed that the FAPF median remained stable over time (Median $=5, p=0.08$ ). The presence of urinary incontinence was reported by $40 \%$ of women in the sample, however, was characterized as mild (i.e. not requiring the use of daily protection). There was also a significant association ( $p=0.001$ ) between the completion of home exercises (twice or more per week) and the normal clinical status. Confounding variables, which could compromise the clinical status, showed no significant association with the outcomes ( $p \geq 0.05)$. Conclusion: Home exercises contributed to the maintenance of continence following a physical therapy treatment.
\end{abstract}

Keywords: urinary continence; woman; physical therapy.

\section{Resumo}

Objetivos: Descrever os resultados da prática de exercícios domicilares para o assoalho pélvico em mulheres continentes nos quesitos avaliação funcional do assoalho pélvico (AFA) e presença de incontinência urinária após um ano de tratamento fisioterapêutico. Métodos: Estudo observacional com 15 mulheres um ano após o tratamento fisioterapêutico para incontinência urinária de esforço (IUE). As variáveis analisadas neste estudo foram: situações de perda urinária, utilização de proteção diária, manutenção dos exercícios domiciliares para o assoalho pélvico, AFA e satisfação da paciente em relação ao tratamento. Também foram investigadas algumas variáveis de confusão, como: estado hormonal, número de partos vaginais e realização de episiotomia. Resultados: Após um ano do término do tratamento fisioterapêutico, observou-se que a AFA manteve-se ( $M d=5 ; p=0,08)$. Quanto à presença de perda urinária, 40\% da amostra relatou ser leve, não sendo necessária a utilização de protetores diários. Observou-se também associação significante $(p=0,001)$ entre a prática de exercícios domiciliares e o quadro clínico normal. As variáveis de confusão, que poderiam comprometer o quadro clínico, não apresentaram associação significativa $(p \geq 0,05)$. Conclusão: A realização dos exercícios domiciliares sugeridos demonstra ser uma variável importante na manutenção da continência urinária ao final do tratamento fisioterapêutico.

Palavras-chave: continência urinária; mulher; fisioterapia.

Received: 12/02/2010 - Revised: 30/09/2010 - Accepted: 03/03/2011

\footnotetext{
Physical Therapist

${ }^{2}$ Physical Therapy Departament, Universidade do Estado de Santa Catarina (UDESC), Florianópolis, SC, Brazil

Correspondence to: Ana Paula Krüger, Rua Antonieta de Barros, 252, Estreito, CEP 88113-710, Florianópolis, SC, e-mail: ana.pkruger@hotmail.com
} 


\section{Introduction $: \therefore$.}

Urinary Incontinence (UI) is defined by the International Continence Society (ICS) as any involuntary loss of urine, being the Stress Urinary Incontinence (SUI) the most common type among women with UI, accounting for $60 \%$ of all cases ${ }^{1}$. In Genuine Stress Urinary Incontinence (GSUI), the involuntary loss of urine through the urethra occurs when the intravesical pressure exceeds the maximum urethral pressure, in the absence of contraction of the detrusor muscle. Such loss occurs when there is an increase in the intra abdominal pressure during efforts such as coughing, sneezing, laughing, walking or jumping ${ }^{2}$.

Numerous surgical techniques ${ }^{3,4}$ and conservative ${ }^{5}$ treatments have been proposed to improve the symptoms of urinary incontinence. Many of them have proven to be effective in the short term, however longitudinal research has not been investigated raising questions about the real significance of the suggested treatments.

Female UI is a common condition that continues to be underestimated. It is believed that 1 in 4 adult women experience UI of varying degrees. According to this estimate, and taking into account the age of the individual, the occurrence of UI among women aged 20 is believed to be around $10 \%$, in women aged over 50 it is $35 \%$, while the occurrence of UI in women aged over 70 -years old can reach $60 \%$. On the other hand, only $20 \%$ to $25 \%$ of these women seek some form of treatment ${ }^{6}$. In a study involving 29,500 women in four European countries, the prevalence of urinary incontinence during the 30 days prior to the interview was found to be $35 \%$. The same study also revealed that in this group of subjects the stress urinary incontinence was the most common type ${ }^{7}$.

In this context, women with symptoms of urinary loss tend to socially isolate themselves, due to the fear of suffering urinary loss in public. In addition, there is a decrease in self-esteem, with women becoming depressed, stressed and irritated ${ }^{8}$.

According to the ICS the first treatment option for this dysfunction should be the rehabilitation of the pelvic floor. With appropriate physical therapy exercises this produces an improvement in symptoms up to $85 \%$ of cases $^{2,9}$. Together with pelvic floor exercises, vaginal cones and endovaginal electro stimulation have produced up to $90 \%$ improvement not only in symptoms, but also in the quality of life of women with SUI ${ }^{9,10}$. Unfortunately, however, there are few public physical therapy services for incontinent women ${ }^{11}$.

One of the main objectives of physical therapy treatment is to increase of urethral resistance and to re-establish the function of the supporting elements of the pelvic organs. The strengthening of the muscles of the pelvic floor is important because the improvement in strength and function in these muscles favors a conscious and effective contraction at times of increased intra-abdominal pressure, which might avoid urinary loss. Appropriate contractions of these muscles contribute positively to improving their tonus and to the transmission of the pressure from the urethra, reinforcing the mechanism of urinary continence $\mathrm{e}^{12,13}$.

A reduction in surgical procedures led to an increase in frequency of conservative treatments for SUI. The effectiveness of such treatments has been extensively confirmed ${ }^{9,11}$, however, to date, few studies examined the maintenance of treatment outcomes following the end of conservative intervention. Based on this argument, the aim of this study was to describe the impact of home exercise for the pelvic floor in continent women, on functional assessment of the pelvic floor and the presence of urinary incontinence, one year after the end of physical therapy treatment.

\section{Methods::}

\section{Research design}

This is an observational study, aiming at the investigation of urinary continence behavior one year after the end of a conservative treatment.

\section{Participants}

The study included 15 women who had undergone previous physical therapy treatment for SUI. This treatment consisted of exercises for training the pelvic floor (fast and slow fibers), which was carried out in supine, seated and orthostatic positions, with endovaginal electrical stimulation. At the end of the intervention, the patients were advised to perform the proposed exercises at least three times per week at home. The proposed home exercises are shown in Appendix 1.

The patients were selected through medical records and according to the following inclusion criteria: a score in the Functional Assessment of the Pelvic floor (FAPF) of grade 5 and absence of symptoms of urinary losses during daily activities such as sneezing, coughing and laughing, at the time of discharge from physical therapy. The patients who met these criteria were contacted by telephone and invited to participate in the study on urinary continence behavior to be reassessed. All of the women received physical therapy treatment at the outpatient service named 'Physiotherapy Applied to Urinary Incontinence', which is a collaboration, between the Centre for Health Sciences and Sport of the Universidade do Estado de Santa Catarina (UDESC), Florianópolis, SC, Brazil and the 
Public Maternity Hospital of Florianópolis. The Ethics Review Committee of the UDESC (protocol number 25/2007) approved study and all participants signed an informed consent form prior to data collection.

\section{Outcomes and variables investigated}

We used the same form at baseline and one year following discharge evaluations to describe the participants' characteristics regarding urinary incontinence. The sample was described according to the variables: age, physical activity, sexual activity, situations that caused urinary leakage, use of daily protection, weight gain and episodes of urinary tract infection, through open-ended questions. The characteristics of urinary continence were investigated by considering the following variables: FAPF, presence of urinary incontinence and frequency of home exercises for the pelvic floor. The variables hormonal status, number of vaginal deliveries and performance of episiotomy were included in the analysis as possible confounders. Subjective evaluation of the patient with regards to the results of physical therapy treatment after one year was categorized as satisfied or not satisfied.

Pelvic floor function (FAPF) was measured by digital palpation and was classified accordingly (see Table 1 for details). The measurements were undertaken by the same examiner who performed the procedure one year prior to the study. The patients were positioned in supine, with the hips flexed and abducted (lithotomic position). The examiner, worn a pair of gloves placing a small quantity of gel on the index and middle fingers and inserted two fingers around $3.5 \mathrm{~cm}$ into the vaginal introitus; this is often the point at which there is a greater perception of pressure during contraction of the pelvic floor ${ }^{15}$.

The tonic fibers were assessed by instructing the subject to perform a maximal sustained contraction. After a practice attempt, subsequent contractions were classified for the FAPF. If the patient maintained the contraction against resistance for 5 seconds or more, this represented a score of FAPF grade 5. During the measurements the patient was instructed to avoid hip swings and contractions of the musculature of the gluteus and hip adductors.

The participants were considered "clinically modified" when the FAPF has decreased and/or if the patient had a recurrence of urinary incontinence one year after the end of physical therapy treatment.

\section{Statistical analysis}

We used descriptive statistics for mean values and percentages, and inferential statistics by means of Fisher's Exact Test to determine the association between the clinical status (normal and altered) one year after physical therapy treatment and
Table 1. Functional assessment of the pelvic floor - FAPF*.

\begin{tabular}{l|l}
\hline \multicolumn{2}{l}{ Functional Assessment of Pelvic Floor - FAPF } \\
\hline 0 & No objective perineal function, even to palpation. \\
\hline 1 & Objective perineal function absent, detectable only by palpation. \\
\hline 2 & Weak objective perineal function, detectable by palpation. \\
\hline 3 & Objective perineal function, without resistance to palpation. \\
\hline 4 & Objective perineal function and resistance not maintained by palpation. \\
\hline 5 & $\begin{array}{l}\text { Objective perineal function and resistance by palpation maintained for } \\
\text { more than } 5 \text { seconds. }\end{array}$ \\
\hline
\end{tabular}

${ }^{*}$ According to Moren $0^{8}$.

the frequency of home exercises, and other variables that could confound the outcome. The Cramer's V coefficient was calculated to identify the magnitude of the associations of nominal variables. The predictive value of one variable on another is given by the squared coefficient $\left(\mathrm{V} \mathrm{Cramer}^{2}\right)$. We also used the Wilcoxon test, with significance level of $5 \%$ to compare the differences in FAPF scores before and after one year.

\section{Results $: \therefore$.}

The mean age of the participants was 55.79 years ( $\mathrm{SD} \pm 12.49$; range 34-75). Regarding physical activity, nine women (60\%) reported walking as their only physical activity. With regards to sexual activity, ten patients (71.4\%) remained sexually active after one year. With regards to weight gain or episodes of urinary infection during the one-year interval after treatment, none of the women reported any occurrence.

In the year following discharge from physical therapy treatment, nine women (60\%) remained free of clinical complaints of urinary losses, while six (40\%) exhibited some form of urinary loss. All of the patients who presented urinary loss reported that these events were small in volume (drops) and the women did not use any kind of daily protection to keep themselves dry.

Of the patients who were discharged from treatment with FAPF value equal to grade 5, twelve (80\%) remained with the same FAPF grade, while three (20\%) deteriorated to grade 4. The median before and after the period of one year did not change (5) and, there was no statistically significant difference between these two periods $(\mathrm{p}=0.08)$.

To verify the association between the clinical status one year after the end of physical therapy treatment with the confounding variables: frequency of home exercises, age, hormonal status, normal childbirth and previous episodes of episiotomy the Fisher's Exact Test was used, which is presented in Table 2. The clinical status was considered normal when the FAPF has remained as grade 5 and there were no complaints of urinary incontinence after one year of physical therapy treatment.

We observed a significant association between the frequency of home exercises (twice or more per week) and maintenance of 
Table 2. Association between the clinical status after one year of physical therapy treatment.

\begin{tabular}{|c|c|c|c|c|c|c|c|}
\hline & & linical & stz & itus & & & \\
\hline Variable & & rmal & & ered & $P$ value & ramer's V & Effect \\
\hline & $n$ & $\%$ & $n$ & $\%$ & & & \\
\hline Frequency of Home Exercises & & & & & & & \\
\hline Once per week & 1 & 14.3 & 6 & 85.7 & $0.001^{*}$ & 0.873 & $76.2 \%$ \\
\hline Twice or more per week & $8^{\dagger}$ & 100.0 & 0 & 0.0 & & & \\
\hline Age & & & & & & & \\
\hline Up to 59 years & 6 & 60.0 & 4 & 40.0 & 1.000 & - & -- \\
\hline 60 years or more & 3 & 60.0 & 2 & 40.0 & & & \\
\hline Hormonal state & & & & & & & \\
\hline Menopause & 6 & 54.5 & 5 & 45.5 & 0.604 & - & -- \\
\hline No Menopause & 3 & 75.0 & 1 & 25.0 & & & \\
\hline Normal childbirth & & & & & & & \\
\hline Up to 2 normal childbirth & 3 & 42.9 & 4 & 57.1 & 0.315 & - & -- \\
\hline 3 normal childbirths or more & 6 & 75.0 & 2 & 25.0 & & & \\
\hline Episiotomy & & & & & & & \\
\hline Yes & 4 & 66.7 & 2 & 33.3 & 1.000 & - & -- \\
\hline No & 5 & 55.6 & 4 & 44.4 & & & \\
\hline
\end{tabular}

Effect=Cramer's V2; 'Residual Adjusted $\geq 2.0 ;{ }^{*} p \leq 0.05$.

the clinical status ( $\mathrm{p}=0.001$ - Table 2). According to the measure of effect (Cramer's $\mathrm{V}^{2}$ ), approximately $76.2 \%$ of the variation in frequency of women with clinical alterations could be explained by the home exercises performed weekly. The variables that could influence the maintenance of urinary continence were not associated with participants' clinical status ( $\mathrm{p} \geq 0.05)$.

Subjective evaluation of the patient regarding the results of physical therapy after one year revealed that fourteen (93.3\%) continued to be satisfied with their conservative treatment, while one (6.6\%) reported that her condition one year after had worsened, in comparison to the time of discharge.

\section{Discussion $: \because$.}

Problems related to the diagnosis and treatments with regards to SUI are still common. Despite of new treatment modalities and the development of surgical techniques, failure rates five years after surgery are as high as 15 to $20 \%$, independently of the procedure and/or the ability of the surgeon ${ }^{16}$.

The current interest in conservative treatment for urinary incontinence has grown due to its greater awareness among incontinent women, the high costs and potential morbidity following surgical procedures ${ }^{14,17}$. The physical therapy treatment given to the participants from the present observational study is widely described in the literature ${ }^{2,16}$, and it is considered effective for urinary loss due to stress. However, to date, the persistence of its clinical benefits in the long-term is still unclear ${ }^{18,19}$.

The age of the patients in this study ranged from 34 to 75 years. A randomized controlled trial performed by Shamliyan et al. ${ }^{20}$ observed that the estimated age range for women with UI varied between 19 years (about 19\% of the sample) and 65 years or more (corresponding up to 30\%), thus, corroborating with the descriptive characteristics of our study's participants.

One year after the end of physical therapy treatment, nine (60\%) women did not have urinary loss. Of the six women who reported loss in response to stress three mentioned that it happened during sneezing, two had loss of urine while coughing and one experienced it in both situations. Considering the recurrence of symptoms of urinary incontinence in situations of coughing and sneezing, this finding corroborates those of Amaro and Gameiro ${ }^{21}$ and Fozzatti et al. ${ }^{15}$, in whose work, episodes of urinary losses after treatment also occurred at moments of sneezing and coughing.

Most daily activities are conducted with individuals in orthostatic position and, as a result, considering the constant action of gravity on the pelvic floor, the complaints of urinary losses are often exacerbated ${ }^{22}$. Fozzatti et al. ${ }^{15}$, on a reassessment of 26 women, 6 months after the end of a conservative treatment for SUI named Global Postural Re-education, found that six participants (24\%) continued to be symptom-free, sixteen women (64\%) continued to experience significant improvement and three women (12\%) did not show any further improvement.

With regards to the use of absorbent pads, Figueiredo et al. ${ }^{23}$ highlighted the fact that the use of pads only minimize the discomfort of SUI patients, but it is necessary to avoid its prolonged use, as this can predispose the patient to the occurrence of epithelial damage, hyperactivity of the detrusor and urinary infection. These complications were not reported by any of the participants of the present study during the one-year follow-up period.

Urinary loss has been shown to occur among physically active women. Caetanos et al. ${ }^{24}$ study observed that $20 \%$ of the participants stopped participating in physical activity because of UI, $18 \%$ changed their activities and 55\% started using pads during exercise. Health care professionals should propose strategies, based upon the woman's general health, that might enable incontinent women to take part in physical activity programs in order to continue enjoying their benefits.

In our study, $60 \%$ of the patients walk as their main modality of physical activity, which is not considered a high-impact activity. According to Silva et al. ${ }^{25}$, the problem of SUI in physically active women has been reported mainly among participants in highimpact sports. In an investigation of 144 nullipara athletes ${ }^{25}, 28 \%$ $(\mathrm{n}=40)$ experienced episodes of UI during exercise, with the activities considered as most likely to cause urinary loss being jumping with the legs apart (30\%), jumping with the legs close to each other (28\%), running (30\%) and sports involving ground impact (14\%).

Caetano et al..$^{24}$ also described that it is crucial to discuss the situation of training and ways to motivate the patient carry out series of home exercises, in order to promote their well-being through enjoyable and regular physical activity. In this context, 
another widely discussed concept concerns the relationship between general physical condition and the development of the perineum muscles. According to Higa et al. ${ }^{26}$ it is widely accepted that women in good general physical condition are more likely to have a stronger perineal musculature and, for this reason, lowimpact exercises are recommended.

A total of $71.4 \%$ of the patients had regular sexual activity being all of them younger than 55 years. Caetano et al. ${ }^{24}$ stated that urinary incontinence is more serious for elderly women, leading these woman to associate UI with the end of their sex lives, and also to loosing control over her body.

It can be argued that performing the proposed exercises at home influenced positively the maintenance of continence, with better results when they took place more than once per week, and being significantly differently from results obtained with less frequent exercise $(p=0.001)$. The three participants who reported carrying out the home exercises "rarely" or who "did not perform them" exhibited a reduction in the FAPF scores (from 5 to 4).

Fozzatti et al. ${ }^{15}$, Bo and Talseth ${ }^{27}$ and Holley et al. ${ }^{28}$ confirmed the improvement of symptoms of SUI through training of the pelvic floor muscles; however, they stated that these exercises are needed to be performed on a regular basis in order to maintain their benefits. The problem is that most women tend to stop exercising after the physical therapy program.

This was also observed in our study, with six patients who reported some kind of symptom of urinary loss carried out the suggested exercises only once a week.

Bo et al. ${ }^{18}$ examined the adherence of patients to exercise programs for pelvic floor 15 years after treatment. The authors observed a low adherence, with only $28 \%$ performing the exercises weekly. For Amaro et al. ${ }^{29}$, both the results and the maintenance of the effects of conservative treatment depended on the interest and motivation of the patients, as well as the willingness of health care professionals to continue supervising these patients. According to Bo and Talseth ${ }^{27}$, patient's adherence to a physical therapy program is the key element for obtaining success both during and after the end of treatment. $\mathrm{Cook}^{30}$ and Cammu et $\mathrm{al}^{31}{ }^{31}$ argued that follow-up in the form of group exercise therapy is more effective than exercises performed at home, because the treatment is not subjected to domestic interruptions, and because people tend to exercise more effectively in the presence of other patients.

With the use of a questionnaire, Bo and Talseth ${ }^{27}$ found that 5 years after the end of conservative treatment $75 \%$ of the women who received treatment did not report any urinary loss. These patients carried out their exercises at least once per week and remained satisfied with their condition. Hahn et al. ${ }^{32}$ offered conservative treatment to 170 women with SUI and seven years later $11 \%$ of the women remained symptom-free, while $44 \%$ described that their condition had improved and $14 \%$ of the sample stated that their symptoms of SUI had returned.
Among the 49 women interviewed by Datillo ${ }^{33}$ one year after the end of conservative treatment, $53 \%$ were still continent, but $38 \%$ reported improvements as a result of the treatment. Furthermore, $69 \%$ of the sample continued to perform their home exercises once or more per week. Meanwhile, in a study performed by Cammu et al. ${ }^{31}$ aimed to determining the situation of continence 10 years after the end of conservative treatment in 49 women, $53 \%$ were found to be continent, while $47 \%$ presented recurrence of symptoms.

In a follow up study conducted by Schiøtz et al. ${ }^{34}$, after ten years of conservative treatment for urinary incontinence, it was found that among 33 patients, only five women were still exercising at least twice a week, 15 women underwent surgery and among the 18 who had not undergone surgery, only six remained continent.

Regarding satisfaction with physical therapy results, 93.3\% (14 patients) of the patients investigated in our study reported an improvement in the symptoms of UI. Only one patient considered the condition of urinary loss unaltered, since their condition of continence had regressed one year after discharge from physical therapy. Bo and Talseth ${ }^{27}$ found that 5 years after the end of treatment $61 \%$ of the group considered themselves satisfied with their condition. Cammu et al. ${ }^{19}$ reported that out of the 45 women treated with strengthening of the pelvic floor, $77 \%$ would recommend the treatment to friends and family members.

The small sample size ( $\mathrm{n}=15$ women) was considered a limitation of this study, as well as the use of subjective methods of evaluation and re-evaluation. However, it becomes relevant to communicate results such as ours, with a follow-up period, since there are few results about the characteristics of urinary continence after physical therapy treatment and its association with home exercise in Brazil. It is further recommended that validated instruments be used to replace questionnaires used to inform about outcomes such as sexual function and quality of life. In addition, other assessment scales for perineal muscle function can also be used.

After one year of physical therapy treatment, we observed that the FAPF median remained constant $(p=0.08)$. The presence of urinary incontinence was reported by $40 \%$ of women from our sample, however, their losses was characterized as mild (drops), not requiring the use of daily protection. There was also a significant association ( $\mathrm{p}=0.001)$ between the performance of home exercises (twice or more per week) and the "normal" clinical status, characterized as the absence of urinary incontinence and FAPF unchanged. Confounding variable, which could compromise the clinical status, showed no significant association $(p \geq 0.05)$.

\section{Acknowledgements : :}

To all of the team involved in the outpatient project: Physical Therapy Applied to Urinary Incontinence. 


\section{References $:: 0$}

1. Abrams P, Cardozo L, Fall M, Griffths D, Rosier P, Ulmsten U, et al. The standardization of terminology in lower urinary tract function: report from the standardization sub-committee of the International Continence Society. Urology. 2003;61:(1)37-49.

2. Bernardes NO, Peres FR, Souza ELBL, Sousa OL. Métodos de tratamento utilizados na incontinência urinária de esforço genuína: um estudo comparativo entre cinesioterapia e eletroestimulação endovaginal. Rev Bras Ginecol Obstet. 2000;22(1):49-54.

3. Daneshgari F. Surgical treatment of female stress urinary incontinence, decades learned lessons. Eur Urol. 2010; 58(2):238-41.

4. Krofta L, Feyereisl J, Velebil P, Otcenásek M, Kasíková E, Krcmár M. TVT-S for surgical treatment of stress urinary incontinence: prospective trial, 1-year follow-up. Int Urogynecol J. 2010;21: 779-85.

5. Hay-Smith EJC, Dumoulin C. Entrenamiento muscular del suelo pelviano versus ningún tratamiento, o tratamientos de control inactivo, para la incontinência urinaria en mujeres. Reproducción de una revisión Cochrane, traducida y publicada en La Biblioteca Cochrane Plus. 2008.

6. Pantazis K, Freeman RM. Investigation and treatment of urinary incontinence. Current Obstetrics \& Gynaecology. 2006;16(6):344-52

7. Hunskaar S, Lose G, Sykes D, Voss S. The prevalence of urinary incontinence in women in four European countries. Bju International. 2004;93:(3)324-30.

8. Moreno AL. Fisioterapia em ginecologia. São Paulo: Manole; 2004.

9. Rett MT, Simões JA, Herrmann V, Gurgel MSC, Morais SS. Qualidade de vida em mulheres após tratamento da incontinência urinária de esforço com fisioterapia. Rev Bras Ginecol Obstet. 2007;29(3):134-40

10. Yamanishi T, Yasuda K. Electrical stimulation for stress incontinence. Int Urogynecol J. 1998:9(1):281-90

11. Guarisi T, Pinto Neto AM, Osis MJ, Pedro AO, Paiva LHC, Faúndes A. Incontinência urinária entre mulheres climatéricas brasileiras: inquérito domiciliar. Rev Saúde Pública. 2001;35(5):428-5.

12. Dwyer PL. Differentiating stress urinary incontinence from urge urinary incontinence. Int $J$ Gynaecol Obstet. 2004;86 Suppl 1:S17-24.

13. Hay-Smith EJC, Ryan K, Dean S. The silent, private exercise: experiences of pelvic floor muscle training in a sample of women with stress urinary incontinence. Physiotherapy. 2007:93(1)53-61.

14. Bø K. Is There Still a Place for Physiotherapy in the Treatment of Female Incontinence? EAU Update Series. 2003;1(3):145-53

15. Fozzatti MCM, Palma P, Herrmann V, Dambros M. Impacto da reeducação postural global no tratamento da incontinência urinária de esforço feminina. Rev Assoc Med Bras. 2008;54(1): $17-22$.

16. Hermann V, Potrick BA, Palma PCR, Zanettini CL, Marques A, Netto Júnior NR. Eletroestimulação transvaginal do assoalho pélvico no tratamento da Incontinência Urinária de Esforço: Avaliações clínica e ultra-sonográfica. Rev Assoc Med Bras. 2003;49(4):401-5.
17. Ramos JGL, Xavier NL, Nácul AP, Zucatto ÂE, Hentschel EL. Comparação dos resultados do tratamento Cirúrgico da Incontinência Urinária de Esforço por três diferentes técnicas cirúrgicas. Rev Bras Ginecol Obstet. 2000;22(1):43-8.

18. Bo K, Kvarstein B, Nygaard I. Lower urinary tract symptoms and pelvic floor muscle exercise adherence after 15 years. Obstet Gynecol. 2005;105(5 Pt 1):999-1005

19. Cammu H, Van Nylen M, Amy JJ. A 10-year follow-up after Kegel pelvic floor muscle exercises for genuine stress incontinence. BJU Int. 2000;85(6):655-8

20. Shamliyan TA, Kane RL, Wyman J, Wilt TJ. Systematic review: randomized, controlled trials of nonsurgical treatments for urinary incontinence in women. Ann Intern Med. 2008;148(6):459-73.

21. Amaro JL, Gameiro M00. Tratamento não cirúrgico da incontinência urinária de esforço. Jornal da Incontinência Urinária Feminina. 2003;7(5):24-8

22. Dietz HP, Clarke B. The influence of posture on perineal ultrasound imaging parameters. In Urogynecol J Pelvic Floor Dysfunct. 2001;12(2):104-6.

23. Figueiredo EM, Lara JO, Cruz MC, Quintão DMG, Monteiro MVC. Perfil sociodemográfico e clínico de usuárias de Serviço de Fisioterapia Uroginecológica da rede Pública. Rev Bras Fisioter. 2008;12(2):136-42.

24. Caetano AS, Tavares MCGCF, Lopes MHBM. Incontinência urinária e a prática de atividades físicas. Rev Bras Med Esporte. 2007;13(4):270-4

25. Silva LH, Serezuella KC, Bordini A, Citadini JM. Relação da incontinência urinária de esforço com a prática de atividade física em mulheres nulíparas. Salusvita. 2005;24(2):195-206.

26. Higa R, Lopes MHBM, Reis MJ. Fatores de risco para incontinência urinária na mulher. Rev Esc Enferm USP. 2008;42(1):187-92.

27. Bo K, Talseth T. Long term effect of pelvic floor muscle exercise 5 years after cessation of organized training. Obstet Gynecol. 1996;87(2):261-5.

28. Holley RL, Varner RE, Kerns DJ, Mestecky PJ. Long term failure of pelvic floor musculature exercises in treatment of genuine stress incontinence. South Med J. 1995;88(5):507-602.

29. Amaro JL, Wroclawski ER, Rios LAS, Kawano PR. Incontinência urinária de esforço: tratamento não cirúrgico e não farmacológico. Projeto Diretrizes. Sociedade Brasileira de Urologia; 2006.

30. Cook T. Group treatment of female urinary incontinence: literature review. Physiotherapy. 2001;87(5):226-34.

31. Cammu H, Van Nylen M, Blockeel C, Kaufman L, Amy JJ. Who will benefit pelvic floor muscle training for stress urinary incontinence? Am J Obstet Gynaecol. 2004;191(4):1152-7.

32. Hahn I, Milsom I, Fall M, Ekelund P. Long term results of pelvic floor training in female stress urinary incontinence. Br J Urol. 1993;72(4):421-7.

33. Datillo J. A long-term study of patient outcomes with pelvic muscle re-education for urinary incontinence. J Wound Ostomy Continence Nurs. 2001;28(4):199-205.

34. Schiøtz HA, Karlsen JH, Tanbo TG. Ten-year follow-up after conservative treatment of stress urinary incontinence. Int Urogynecol J Pelvic Floor Dysfunct. 2008;19(7):911-5.

Appendix 1. Home exercises for the pelvic floor.

\begin{tabular}{|ll|}
\hline Position & Action* \\
\hline $\begin{array}{l}\text { Patient sitting on a chair with the hips abducted, knees flexed at } 90 \text { degrees and } \\
\text { feet flat on the floor. Spine should remain upright with hands placed on the knees. }\end{array}$ & $\begin{array}{l}\text { Perform a deep inspiration with the hips abducted with hands and knees during ex- } \\
\text { piration perform hip adduction against a pillow, associated with perineal contraction. }\end{array}$ \\
\hline Patient seated, knees and hips flexed at 90 degrees and hands on the knees. & $\begin{array}{l}\text { Perform a deep inspiration and during expiration and held the position change } \\
\text { to the standing position, associated with perineal contraction. }\end{array}$ \\
\hline $\begin{array}{ll}\text { Patient on a standing position, supporting the feet positioned on a step ahead. } \\
\text { The contralateral knee remains extended. }\end{array}$ & $\begin{array}{l}\text { Perform a deep breath in this position and during expiration climb the step } \\
\text { involving the movement to contraction perineal }\end{array}$ \\
\hline $\begin{array}{l}\text { Patient on a standing position, leaning on a cane before her. The hip abduction } \\
\text { and knee remains slightly bent contraction. }\end{array}$ & $\begin{array}{l}\text { Perform a deep breath in this position and during expiration hold a small squat } \\
\text { by flexing hips and knees, associated with perineal. }\end{array}$ \\
\hline
\end{tabular}

*Oriented to the patients who carried out about three sets of ten rapid contractions and three sets of ten contractions slow (three seconds) of the perineal muscles. The patient should realize the only contraction of the perineum, isolating the muscles of the adductor region, abdominal and gluteus regions, as taught during the sessions of physical therapy 